\title{
"OBRIGADO POR EXISTIR": UM ESTUDO PSICANALÍTICO ACERCA DO SENTIMENTO DE GRATIDÃO NAS RELAÇÕES AMOROSAS
}

Thassia Souza Emidio UNESP - Campus Assis

\section{Jussara Aparecida Rodrigues}

UNESP - Campus Assis

\begin{abstract}
Resumo
O presente artigo objetiva compreender e investigar os sentidos atribuídos ao sentimento de gratidão por sujeitos que vivenciam a experiência de uma relação amorosa na atualidade. Esse estudo baseia-se numa pesquisa qualitativa que empregou a entrevista semidirigida como instrumento de coleta de dados, visando refletir acerca da presença e do desenvolvimento da gratidão em meio às relações amorosas em que se encontram os sujeitos no contemporâneo. Os resultados expressaram dúvidas e questionamentos, mostrando a gratidão como um sentimento difícil de ser pensado e experienciado, mas que também figura como algo presente e de grande importância na vida e relações desses sujeitos.
\end{abstract}

Palavras Chaves: Gratidão, relações amorosas, contemporâneo.

\section{"THANKS FOR EXISTING": A PSYCHOANALYTIC STUDY ABOUT THE FEELING OF GRATITUDE IN LOVE RELATIONSHIPS}

\begin{abstract}
This article aims to understand and investigate the meanings attributed to the feeling of gratitude by subjects who experience the experience of a loving relationship. This study is based on a qualitative research that used the semi-structured interview as an instrument of data collection, aiming to reflect about presence and development of gratitude in the midst of the fragile relationships that contemporary subjects find themselves. The results expressed doubts and questions, showing the gratitude as a difficult feeling to be thought as well as experienced, but which also appears as something present and of great importance in the life and relationships of these subjects.
\end{abstract}

Keywords: Gratitude, love relationship, contemporary.

\section{"GRACIAS POR EXISTIR": UN ESTUDIO PSICOANALÍTICO ACERCA DEL SENTIMIENTO DE GRATITUD EN LAS RELACIONES AMOROSAS}

\begin{abstract}
Resumen
En este artículo se pretenden comprender e investigar los sentidos atribuidos al sentimiento de gratitud por sujetos que experimentan la experiencia de una relación amorosa. Este estudio se basa en una investigación cualitativa que empleó la entrevista semidirigida como instrumento de recolección de datos, para reflejar la presencia y el desarrollo de la gratitud en medio de las relaciones frágiles que se encuentran los sujetos contemporáneos. Los resultados expresaron dudas y cuestionamientos, mostrando la gratitud como un sentimiento difícil de ser pensado, pero que también figura como algo presente y de gran importancia en la vida y relaciones de esos sujetos.
\end{abstract}

Palabras clave: Gratitud, relación amorosa, contemporáneo

\section{INTRODUÇÃO}

No decurso da história, o amor foi sendo concebido e representado de acordo com cada povo e sua cultura. Assim, as relações amorosas foram 
constituindo e estabelecendo-se conectadas ao contexto histórico e cultural da sociedade. Aos sujeitos foram apresentadas mudanças e diversos sentidos para se viver, configurando novas formas de produção de subjetividade assim como novos modos de se relacionar.

Muitas foram as mudanças ocorridas em nossa sociedade que tiveram ressonâncias nas formas de se vincular: a revolução sexual que contribuiu para a queda da hierarquia entre os homens e as mulheres, a inserção da mulher no mercado de trabalho, a invenção da pílula anticoncepcional; a instituição da lei que permite o divórcio; o avanço social que ocasionou mudanças nos modos de subjetivação, como o avanço tecnológico, o narcisismo, o individualismo, o consumismo, a fragilidade como efeito de um mundo em que a família e a coletividade foram se enfraquecendo.

Nesse cenário, a família também se transformou, trazendo novos arranjos e possibilidades de vinculação e na atualidade, muito se discute sobre as funções parentais, os vínculos familiares e suas ressonâncias no estabelecimento do vínculo amoroso. Zanetti e Gomes (2011) apontam que as relações familiares se tornaram mais frágeis e inseguras e que o papel dos pais nesse meio tornou-se fragilizado, já que com o desenvolvimento de uma racionalidade científica e do atravessamento de diversos saberes na vida familiar, os pais foram destituídos de seu lugar de saber e colocados diante de impasses e inseguranças no exercício de sua função. As referidas autoras, chamam esse processo de fragilização das funções parentais e colocam que este ocorreu devido a determinantes históricos, socioculturais e econômicos que contribuíram para as mudanças no comportamento dos pais de hoje.

O exercício da parentalidade trouxe uma dificuldade de apoderar-se de todas as mudanças ocorridas na sociedade ao longo do tempo, levando muitos pais a apresentarem dificuldades de oferecer uma educação não rígida e também de não reconhecer que as crianças, mesmo muito pequenas, precisam de orientação, limite e respeito de acordo com suas capacidades e possibilidades. Zanetti e Gomes (2011) colocam que há uma dificuldade de se estabelecer limites, ficando os sujeitos imersos em suas projeções narcísicas e impossibilitados de lidar com suas frustrações. Oliveira (2006) aponta que a fragilização das funções parentais vem acompanhada de uma negação da alteridade, e essa dificuldade de vivenciar a frustração, de tolerá-la e de estabelecer limites nas relações, tem levado a uma acentuação do posicionamento narcísico que é apontado como uma característica da sociedade hoje.

No campo das relações amorosas, Rossi (2003) coloca que na atualidade ninguém tem a obrigação de ficar com ninguém, tendo a liberdade de escolher o parceiro e como irá investir na relação, e a busca deste se baseia na possibilidade de desenvolver-se pessoalmente. Rossi (2003), Lipovetsky (2005), Costa (1998) e Ramos (2003) colocam que hoje a busca por um parceiro está 
cercada pela ilusão de só se obter o prazer, a completude, o que mostra a dificuldade do sujeito em lidar com as frustrações e com o que vem do outro.

Bauman (2004) reflete sobre essa liquidez do amor em nossa sociedade pontuando que, apesar do indivíduo buscar uma conexão com o outro na tentativa de completar a falta ocasionada pela perda de construções sólidas, tal conexão pode se dar de maneira frouxa e se desfazer a qualquer momento. 0 sujeito contemporâneo se encontra desesperado por ter de contar consigo mesmo, já que as condições sociais em que está imerso não Ihe oferecem mais uma segurança.

Tais autores se referem ao amor na contemporaneidade como algo em constante movimento, fluído, em que a conexão e a desconexão com o outro pode acontecer a qualquer momento, se ligando ao desejo de volta-se para si, na busca constante da própria satisfação. (Bauman, 2004).

Em decorrência dessa nova modalidade de amar, a vontade de receber pode ser maior que a de oferecer o mesmo para o outro, como discorre Ramos (2003). Assim, se o outro não oferece o que se é desejado, é descartado como uma mercadoria dentro da lógica de consumo que permeia a sociedade atual. A tecnologia, o narcisismo, o individualismo e o consumismo são apontados por Zanetti (2012), baseada em autores como Baudrillard (2007); Bauman (2001, 2004); Costa (2003); Lipovetsky (2005) e Sá, Mattar e Rodrigues (2006), como fenômenos contemporâneos que devem ser discutidos quando pensamos nos relacionamentos amorosos.

O consumismo pouco se conecta à ideia de subsistência, não se consome para satisfazer-se em suas necessidades básicas, mas sim por um desejo que tem a si mesmo enquanto motivo para o consumo. O consumismo segundo Bauman (2001) se revela como um movimento, uma tentativa do sujeito de tamponar a sua condição desamparada, um modo de lidar com a instabilidade e a insegurança que o rodeiam. A tecnologia, por sua vez, funciona também como uma tentativa de aplacar a angústia do vazio em que se encontram imersos os sujeitos na atualidade. Sá, Mattar e Rodrigues (2006) colocam que a tecnologia acabou por distanciar o sujeito de suas bases coletivas, o levando a se aproximar da ideia de controle sobre o outro a partir de uma ilusão de proximidade oferecida por dispositivos eletrônicos cada vez mais modernos e interativos. Nesse sentido, o sujeito começa a se relacionar com o outro de maneira temporária, procurando na relação algum tipo de benefício e permanecendo nela enquanto o outro ainda está sendo de alguma utilidade.

O narcisismo pensado como um fenômeno contemporâneo, é discutido por Zanetti (2012) a partir da obra de Freud (1914/1996) na qual o referido autor discute o narcisismo a partir da concepção de narcisismo primário, como uma condição inicial do sujeito, um momento do desenvolvimento pelo qual todos passam, e a do narcisismo secundário um processo no qual o sujeito volta a sua libido para si, buscando a vivência de prazer, e a evitação do desprazer a partir 
de um autoinvestimento. Partindo das acepções freudianas, Costa (2003) busca a partir de uma articulação entre Freud (1914/1996) e Lasch (1983), refletir sobre o narcisismo como um sintoma social.

Costa (2003) coloca que em um cenário onde tudo é permeado pela brevidade e pela incerteza, a defesa narcísica pode ser vista como uma solução diante dos impasses que se apresentam, sendo necessário que se entenda o narcisismo também em seus aspectos sociais, pois para o autor, o narcisismo não se trata apenas de uma relação egoísta com o mundo, como se este fosse apenas um espelho do Eu, de um auto investimento, mas trata-se também de um posicionamento do sujeito diante das mudanças que se apresentaram em nossa sociedade. Para o autor, o narcisismo funciona como uma maneira de reagir ao panorama atual, onde ao não ser possível confiar no mundo, no outro, e ao se sentir desamparado diante da sensação de que o mundo é um lugar inseguro e desagradável, e cheio de incertezas com relação ao futuro, o sujeito volta-se para si, buscando em si o conforto e as certezas não oferecidas em sua relação com o mundo.

Como colocado anteriormente, na contemporaneidade emergem novas formas de amar conectadas às transformações ocorridas ao longo do tempo e nesse cenário, essa nova maneira de amar é definida por Bauman (2004) e Lipovetsky (2005) como uma forma efêmera, vazia, frágil, descompromissada, onde se elucida que o amor passou da estabilidade à instabilidade, acabando por desencantar alguns sujeitos. Porém, alguns ainda desejam se relacionar nos moldes do amor romântico, muitas vezes em busca de viverem um sentimento intenso que os ajudem a lidar com as incertezas e o vazio do panorama atual, já que o amor romântico carrega a ilusão de que haverá uma completude e esta ainda figura no cenário social como o ideal de amor a ser almejado e conquistado.

Sá et al. (2006) colocam que o indivíduo, por desejar se sentir consolado e acolhido encara o outro como estando disponível para uso, requerendo que ele atenda às suas demandas, inclusive do vazio que carrega. Segundo Lins (2012), a ilusão de que cada par é para o outro uma espécie de fonte de compensação, afasta temporariamente o receio de se sentirem desemparados.

Nesse sentido, pode-se dizer que o indivíduo contemporâneo se encontra imerso em diversas contradições: ganhou mais autonomia e liberdade, mas também perdeu os suportes identitários que poderiam ajudá-lo a lidar com essas conquistas, e assim tem se fechado em torno de si mesmo em busca de proteção, recorrendo ao narcisismo enquanto defesa.

Rustin (2000) coloca que para Klein o narcisismo não é uma condição primária de existência como apontado por Freud (1914/1996) e discutido por autores posteriores a ele. Para a autora, o narcisismo é "uma consequência de cisão intensa, em que o self preserva um sentimento onipotente de seu próprio valor para se defender da perda e da dor que surgem do dano ao seu objeto, do 
qual, na realidade ele depende." (Rustin, 2000, p. 198). O narcisismo para Klein vem como uma resposta a perda de seus suportes, recorrendo a si mesmo como fonte de segurança, proteção e satisfação. Nesse sentido, percebe-se que as acepções de Klein sobre o narcisismo, coadunam com as discussões desenvolvidas por autores que se debruçam sobre os modos de vida e relacionamentos na atualidade.

Dentro desse modo de vida onde está presente a liquidez do amor, a brevidade e a dissolubilidade dos relacionamentos, percebe-se uma busca pela experiência de uma relação amorosa e a tecnologia apresenta-se tendo um importante papel: as redes sociais são utilizadas para a demonstração dessa relação de amor. Fotos, declarações, poesias, músicas são postadas em busca de demonstrar e explicitar o amor que se sente pelo outro e um termo que se evidencia nesse movimento é o termo gratidão, que aparece, muitas vezes, se referindo ao agradecimento da presença do parceiro em sua vida. Ferreira-Lemos (2011) coloca que esta apresenta-se como uma outra característica do cenário atual, o uso das redes sociais para a explicitação da vida e da intimidade conjugal. Ao observar-se "os feeds" das redes sociais, percebe-se que vários usuários realizam estas postagens e usam o termo gratidão, como exemplo disso: a hashtag gratidão é usada 5.496 .035 vezes em redes sociais como Instagram (registro de 14/11/2017) e é tema de mais de 30 páginas do Facebook, essas postagens geralmente vem acompanhadas de fotos, declarações de amor, vídeos de momentos vividos e foram elas os fios disparadores das reflexões deste trabalho.

A partir do olhar para o uso do termo gratidão em postagens nas redes sociais relacionadas ao amor e ao relacionamento amoroso considerou-se que apesar do processo de fragilização dos vínculos amorosos e da alteridade, circula pelas redes sociais um discurso de gratidão com relação ao outro, um agradecimento por sua existência e presença na vida entre dois. Nesse sentido, acredita-se ser importante explorar os sentidos atribuídos a esse sentimento de gratidão vivenciado e explicitado nas relações amorosas na contemporaneidade. O que seria então essa gratidão em um cenário onde eu busco que meu parceiro seja apenas espelho de mim? Como pensar a gratidão em relacionamentos amorosos atravessados por uma cultura em que o narcisismo é uma característica? Quais os sentidos desse sentimento nas relações amorosas na atualidade?

Kenberg (1995) coloca que um casal que estabelece uma relação pautada pelo narcisismo, faz esforços para construir uma imagem pública de seu relacionamento e que ela é muitas vezes irreal e traz a imagem de uma relação total e de gratificação mútua, essas relações são pensadas pelo autor como relações nas quais prepondera uma idealização do parceiro e da busca de atributos no outro que tragam a possibilidade dele ser admirado pelos outros e socialmente, o que traz um sentimento de gratificação por aquilo que o outro 
representa. Porém, para pensar a gratidão nesse cenário dos relacionamentos amorosos é necessário retomar o conceito dentro da teoria psicanalítica.

Gratidão é um termo que em Psicanálise foi discutido por Melanie Klein (1957/1996), em seu trabalho Inveja e Gratidão, sendo esta autora a precursora nessas discussões. Segundo o Dicionário de Psicanálise de Roudinesco e Plon (1998, p. 397), gratidão aparece "para definir a natureza interativa e dialética do dualismo amor/ódio", opondo-se a outro termo kleiniano, a inveja. Esses dois sentimentos se configuram como opostos e inter-relacionados, operando, geralmente, desde o nascimento do sujeito, e o primeiro objeto destes dois sentimentos é o seio nutridor. Essa relação com o seio materno "torna-se a base para a dedicação a pessoas, valores e causas e, assim, é absorvida uma certa parte do amor que era inicialmente sentido pelo objeto originário" (Klein, 1957/1996, p. 219).

Ao longo de seu trabalho, Klein ressalta a grande importância da relação do bebê com o seio e a mãe, que acaba por introjetar esse objeto originário no ego, construindo, dessa forma, a base para um desenvolvimento satisfatório, sendo este seio sentido como fonte de nutrição e como a própria vida. A proximidade com o seio gratificador pode restabelecer a unidade perdida com a mãe e o sentimento de segurança, dependendo da capacidade de investir do bebê no seio ou no seu representante (mamadeira), tornando a mãe, o objeto amado. "O seio bom é tomado para dentro e torna-se parte do ego, e o bebê, que antes estava dentro da mãe, tem agora a mãe dentro de si" (Klein, 1957/1996, p. 210).

Esse estado pré-natal, em que o bebê vive um sentimento de unidade e segurança pode não estar livre de perturbações, dependendo das condições físicas e psicológicas em que se encontra a mãe, e de certos fatores que irão marcar a relação dupla vivida com o seio bom e o seio mau. A forma como a mãe alimenta, cuida, lida com a amamentação, se tem dificuldades psicológicas ou se é ansiosa, influenciam na capacidade do bebê de ter prazer para aceitar o leite e de poder internalizar o seio bom. Desse modo, a frustração causada pelo seio se adentra na relação inicial do bebê com o seio, promovendo uma ameaça de aniquilamento do objeto por impulsos destrutivos. "A inveja contribui para as dificuldades do bebê em construir seu objeto bom, pois ele sente que a gratificação de que foi privado foi guardada para uso próprio, pelo seio que o frustrou" (Klein, 1957/1996, p. 212). Esse ataque contra o seio tem como consequência a dificuldade da criança em encontrar no mundo exterior um objeto bom "e por consequência, a edificação por introdução no Eu de um objeto bom, condição necessária para fundar a estabilidade e estabelecer um Eu forte".

É necessário que a capacidade de amar esteja desenvolvida para que a criança consiga sentir satisfação completa, podendo introjetar o seio bom com segurança, sem que esta seja perturbada. "Essa gratificação plena ao seio significa que o bebê sente que recebeu do objeto amado uma dádiva especial 
que ele deseja guardar. Essa é a base da gratidão, que está ligada à confiança em figuras boas" (Klein, 1957/1996, p. 220). Quanto mais a criança sente e aceita a experiência de gratificação advinda do seio, mais esses sentimentos de satisfação e gratidão são sentidos e, em consequência, a vontade de retribuir esse prazer. Se a capacidade de amar estiver desenvolvida, o bebê poderá sentir satisfação completa, dando base para o desenvolvimento da gratidão. Assim sendo, a capacidade de fruir plenamente, na relação inicial com o seio, propicia formar o alicerce para sentir prazer em distintas fontes.

Deste modo, a gratidão é derivada da capacidade de amar, tendo sua origem, na fase mais inicial da infância, a relação de objeto único e exclusivo do bebê com a mãe. É também, essencial na construção da relação com o objeto bom e no "funcionamento da apreciação do que há de bom nos outros e em si mesmo" (Klein, 1957/1996, p. 219). Nessa dinâmica, essa primeira ligação, seria a base para as relações ulteriores com uma pessoa amada. A maneira como é vivenciado o primeiro modelo relacional, tem ressonâncias nas formas como o sujeito estabelece seus vínculos amorosos posteriores, sendo importante ressaltar que esse modo de se relacionar do sujeito, desde o início, é atravessado pelos modos de vida e de subjetivação característicos do período em que vive. Sendo assim, a forma como a mãe e a criança se conectam e as ressonâncias disso em seus vínculos amorosos se ligam também a como essa vivência é construída no cenário social atual.

Klein (1957/1996) aponta que nas relações amorosas, quando adulto, ao identificar-se e fazer sacrifícios por uma pessoa que se ama, esse sujeito desempenha o papel de mãe boa ou pai bom, agindo como os pais se comportavam com esse sujeito ou, como gostaria que os pais tivessem se comportado.

(...) Ao agir com outra pessoa como mãe boa ou pai bom, recriamos e aproveitamos na fantasia o amor e a bondade que tanto desejávamos dos pais. Mas agir como pais bons com outras pessoas também pode ser uma maneira de lidar com as frustrações e sofrimentos do passado (p. 353).

Na dinâmica da relação conjugal, os parceiros vivenciam uma retomada de suas experiências iniciais, como também da vivência edípica, porém, sendo este um novo vínculo, há a possibilidade de reeditá-las, de recriá-las. Os relacionamentos amorosos estão apoiados em situações emocionais arcaicas em relação aos pais, mas são sempre uma nova forma de vinculação, sendo possível a mudança e a elaboração com ela e a partir dela.

Nesse sentido, considera-se que a vivência e o desenvolvimento da gratidão nos relacionamentos amorosos, se conectam aos sentimentos de amor e gratidão que surgiram da relação inicial do bebê com a mãe em resposta aos cuidados e amor desta. É necessário que a ligação com o seio tenha sido 
satisfatória para que consiga internalizar um objeto bom e possa se dedicar e se sentir grato aos outros.

A partir dessas concepções de Klein (1957/1996), surge a questão: se em um cenário onde como apontado anteriormente vivemos um processo de transformação da sociedade e das formas de se relacionar, que levou a fragilização das funções parentais e ao estabelecimento de vínculos pautados pelo narcisismo, como refletir sobre esse vínculo inicial entre a mãe e o bebê e suas ressonâncias nos relacionamentos amorosos hoje? Se como Zanetti e Gomes (2011) apontam as funções parentais passam por um processo de fragilização na atualidade e como coloca Lasch (1983) o narcisismo é uma característica da sociedade, poderíamos dizer que a fragilidade do investimento na relação entre a mãe e o bebê leva o sujeito a uma dificuldade de se sentir grato aos objetos, e de certo modo, essa dificuldade se relaciona também ao narcisismo como uma defesa do sujeito diante de sua condição desamparada frente à toda essa fragilização? Poderíamos pensar também, compreendendo que o enfraquecimento dos processos simbólicos na contemporaneidade (Birman, 2006), e o esvaziamento do pensamento e da reflexão, se relacionam também a essa dificuldade de tolerar os sentimentos de amor e ódio com relação aos objetos iniciais e a dificuldade de suportar a perda e a separação de nosso objeto inicial?

A busca por um parceiro amoroso no cenário atual, marcado pelo narcisismo seria então uma tentativa de receber aquela gratificação não recebida ou perdida com a mãe? É possível se sentir grato nesse cenário do amor permeado pelo narcisismo? Existe gratidão nessas relações, o que as pessoas entendem por esse sentimento?

A partir dessas indagações e da reflexão sobre os relacionamentos amorosos na atualidade é que este estudo buscou explorar e compreender os sentidos atribuídos ao sentimento de gratidão por pessoas que vivenciam relacionamentos amorosos na atualidade. Neste primeiro momento desta pesquisa, buscou-se identificar e compreender o que os entrevistados compreendem por gratidão e como a percebem em seus relacionamentos amorosos e qual a associação que fazem entre o sentimento de gratidão vivido em suas experiências amorosas com o sentimento de gratidão vivido em suas relações no grupo familiar.

\section{MÉTODO}

Trata-se de uma pesquisa qualitativa que tem a Psicanálise como referencial teórico e metodológico. Tratando-se de uma pesquisa que tem a Psicanálise como referência teórica e metodológica, baseado nas discussões de Figueiredo e Minerbo (2006) pode-se considerar como uma pesquisa em psicanálise, aquela na qual a psicanálise serve de aporte teórico para a 
fundamentação da discussão sobre o tema, como também do processo de coleta e análise dos dados.

\section{Participantes}

Participaram da presente pesquisa, 5 pessoas, sendo três mulheres e dois homens, na faixa-etária dos 23 aos 48 anos e que se encontravam em algum tipo de relacionamento amoroso como namoro, noivado, casamento, união estável. O tempo de relacionamento foi considerado como um critério de exclusão, assim, estabeleceu o mínimo de três anos de relação para compor a amostra, pois, assim como Rodrigues (2013) coloca, esse tempo possibilitaria a aproximação de um relacionamento amoroso estável. Os entrevistados foram nomeados com nome fictícios escolhidos por eles após a entrevista, são eles: Julia, 25 anos, estudante de Psicologia e namora a três anos e seis meses. Vanessa, 23 anos, possui ensino superior completo, vive com seu parceiro e mantém esse relacionamento amoroso por quatro anos. Ana, 33 anos, especializada em RH e gestão de recursos humanos, é casada e está na sua relação amorosa faz 13 anos. João, 37 anos, possui ensino superior completo e está com sua parceira a quatro anos, juntando o namoro e o casamento. Pedro, casado, tem 48 anos e ensino superior completo e mantém o relacionamento com sua parceira a vinte quatro anos.

\section{Instrumentos e procedimentos}

O instrumento de coleta de dados utilizado foi a entrevista semiestruturada. Foi elaborado um roteiro prévio com questões sobre o relacionamento amoroso e o sentimento de gratidão, buscando identificar o que os entrevistados entendiam por gratidão, como percebiam esse sentimento em seus relacionamentos amorosos, e qual relação estabeleciam entre a gratidão vivida no relacionamento amoroso com a gratidão vivida na relação com a família.

O contato com os entrevistados se deu de maneira indireta a partir de algum mediador conhecido dos entrevistados. A pesquisa foi aprovada pelo Comitê de Ética em Pesquisa da Faculdade de Ciências e Letras de Assis, protocolo CAE no 55702415.6.0000.5401, sendo apresentado aos participantes o Termo de Consentimento Livre e Esclarecido antes de cada entrevista. As entrevistas foram gravadas e posteriormente transcritas de forma integral e fiel, sendo os nomes trocados por nomes fictícios visando o sigilo e a preservação da identidade dos entrevistados.

\section{Análise dos Dados}

O material obtido foi analisado e discutido buscando uma articulação com as discussões de Klein acerca do sentimento de gratidão em interlocução com as produções de autores que se debruçaram sobre a discussão dos relacionamentos 
amorosos na contemporaneidade. Dessa maneira, buscou-se associar as discussões em Psicanálise concernentes aos temas abordados com os relatos dos sujeitos sobre suas experiências amorosas e sobre o sentimento de gratidão e seus sentidos para estes. E a partir desse exercício, buscou-se também analisar como os sentidos atribuídos ao sentimento de gratidão se articulavam às questões socioculturais ligas ao fenômeno do narcisismo e das novas formas de vinculação que se evidenciam na atualidade. A partir de uma leitura atenta dos relatos das entrevistas, buscou-se identificar os sentidos evidenciados que traziam o caráter de uma contribuição original para o problema de pesquisa. Assim, a análise dos relatos foi transformada em um texto que buscou identificar marcas do discurso e sentidos produzidos articulando às discussões teóricas que referenciam o trabalho, buscando elucidar algo sobre a questão apresentada.

Desta forma, após transcrita, as entrevistas foram lidas de maneira exaustiva em busca de identificar essas marcas e sentidos e assim foram construídas categorias de análise que se organizaram a partir dos conteúdos que foram salientados pelos entrevistados. Organizou-se quatro categorias: 1Olhares sobre o relacionamento amoroso; 2- O que é gratidão; 3- A gratidão e suas raízes; 4- A gratidão nos relacionamentos amorosos. A partir da análise dessas categorias, buscou-se construir uma reflexão acerca dos sentidos da gratidão para os entrevistados, a vivência desta na experiência de uma relação amorosa e sua conexão com a vida familiar e o cenário social atual.

\section{RESULTADOS E DISCUSSÕES}

\section{Categoria 1 - Olhares sobre o relacionamento amoroso}

A partir da análise das entrevistas, pode-se verificar que cada entrevistado trouxe um olhar diferente sobre como é sua relação amorosa. Em sua maioria, relataram terem um bom relacionamento com o parceiro e ressaltaram algumas dificuldades que enfrentam no dia a dia de seu cotidiano amoroso, mas como apontado na fala de Ana, essas divergências seriam normais em qualquer casal.

O relacionamento de Julia é definido para ela como saudável, ela se sente bem com seu namorado e os dois tem espaço para expressar o que sentem e o que acham mesmo sendo algo que o outro não vai gostar. Assim, considera seu relacionamento algo que poucas pessoas possuem. Ana convive bem com o parceiro, mas vivem quase num relacionamento à distância visto que o marido trabalha em outra cidade e por isso se veem pouco. Dessa forma, acabam se vendo geralmente a noite e pela manhã antes dela ir trabalhar.

Os relatos de Júlia e Ana sobre seus relacionamentos amorosos trazem a ideia da formação do par amoroso. As duas ao descreverem a relação amorosa trazem a presença do parceiro em seu discurso indicando que há uma conexão entre o par, possibilitando a construção do que chamamos de vínculo amoroso. 
As duas relatam viver um "relacionamento à distância", mas apontam que esse distanciamento não prejudica a relação, mesmo que estas apresentem divergências que em seus discursos, fazem parte da vida de um casal.

Estas questões de divergências também estão presentes na fala de Vanessa, que aponta que seu relacionamento não é mais 'estilo lua de mel'. Ela relata que é estressante, que se estressa com tudo, mas que isso não quer dizer que não ame seu parceiro. Vanessa ao falar da relação acaba falando mais de si e coloca a relação como um reflexo de sua vida, se ela está bem, a relação vai bem, se ela está mal, a relação vai mal. O que Vanessa coloca coaduna com o que Bauman (2004) aponta sobre os relacionamentos amorosos na atualidade, onde a dificuldade de investimento no outro e na construção de uma conexão entre a dupla amorosa, faz da relação um reflexo, um espelho do que cada um individualmente traz para a relação. A ideia do par amoroso não se apresenta no relato que Vanessa traz de seu laço conjugal, onde prevalecem as descrições de suas próprias características, trazendo em seu discurso uma certa instabilidade que se reflete em uma dificuldade no laço amoroso.

João, ao ser indagado sobre o seu relacionamento amoroso, fala bem pouco acerca de seu casamento, focando mais sobre o cotidiano do casal e coloca em seu discurso a presença dos filhos e da vida corrida que vivencia.

Pedro já discorre mais e traz outra perspectiva para descrever seu relacionamento, conseguindo pensar e refletir acerca dos anos que está com sua parceira e das fases que ele diz que esta relação é formada, tendo uma visão das transformações que ocorreram do início até o momento atual. Por ter o maior tempo de relacionamento amoroso, Pedro consegue, se comparado a todos os outros entrevistados, ter uma maior percepção de sua relação, da sua parceira e da sua família, sendo capaz de compreender e refletir acerca do passar dos anos da sua vida a dois.

Percebe-se nos discursos dos entrevistados que o relacionamento amoroso é visto por esses como uma parceria, onde aspectos positivos e negativos estão presentes, porém relatam ser uma experiência agradável a vida com o parceiro. Com a exceção de Vanessa que coloca a relação centrada no seu posicionamento e vê esta como um reflexo de suas próprias ações.

Porém, percebemos também que ao falar de seus relacionamentos amorosos, com exceção de Pedro, que foca na temporalidade e na parceria com sua esposa, os entrevistados focam mais no cotidiano da vida conjugal, explicitando pouco seus sentimentos em relação aos parceiros e as características da relação, e relatando mais sobre o que vivenciam no dia a dia da vida a dois, questões de rotina e organização da vida. Tal apresentação da vida amorosa focada mais na rotina da vida conjugal do que na experiência de amor leva a reflexão sobre os vínculos amorosos na contemporaneidade e no que Smeha e Oliveira (2013) colocam sobre os sujeitos estarem voltados mais para si, focando em interesses individuais e profissionais, evidenciando uma outra 
forma de vinculação com o par amoroso e como apontada por Rossi (2003) e Bauman (2004), apresentando-se como relações marcadas pelo individualismo e pelo consumismo, onde o parceiro é visto como aquele que pode me oferecer algo para consumir, trazendo o prazer momentâneo e a dificuldade de compartilhamento afetivo e de experiências na convivência a dois, sendo isto demonstrado nas dificuldades do estar junto e de falar acerca da própria relação amorosa a partir dos sentimentos com relação ao outro.

Ao discorrerem sobre seus relacionamentos amorosos, os entrevistados não conseguiram expressar questões relacionadas aos afetos, aos prazeres e às coisas mais íntimas e que compõem o laço amoroso, tratando-o superficialmente, sem se aprofundar, sem falar sobre os sentimentos que o envolve, mostrando as dificuldades de se referir e de discutir a relação amorosa. Estes fatores podem ter ocorrido pela inibição que em algumas vezes as pessoas sentem em uma situação de entrevista, porém os entrevistados pareceram bem à vontade na situação de entrevista, o que leva a pensar que seus discursos evidenciam essa nova forma de vinculação que permeia o cenário atual, relações de distanciamento, marcadas pelo autoinvestimento.

\section{Categoria 2 - O que é gratidão?}

Ao serem questionados sobre o que era gratidão, os entrevistados colocaram nunca terem pensado no assunto ou em como definiriam o termo. Sendo questionados sobre o significado e o sentido deste sentimento em suas vidas, pode-se perceber que este sentimento possui o mesmo significado, mas sentidos diferentes para os entrevistados, sendo considerado algo muito importante, mas que, ao mesmo tempo provoca muitas dúvidas e questionamentos, explicitado na pausa dada por todos para pensar antes de responderem a tais perguntas.

Gratidão é reconhecer o que o outro faz por você, mas a intenção, sabe? Nem tanto o que você recebe, mas a intenção de fazer que aquilo dê certo, a intenção de agradar, a intenção de estar com você, de tentar fazer que aquilo dê certo. (Julia)

João e Julia trazem a gratidão relacionada às atitudes e aos feitos do parceiro. Ana associa a presença do parceiro e o que eu isto traz de bom enquanto que Pedro articula esses dois aspectos em sua resposta.

A gratidão é percebida pelos participantes como uma identificação no parceiro ou na relação das coisas boas e positivas. Para eles, isso estaria associado ao que o outro faz ou representa e é recebido como algo bom, trazendo a satisfação com o que é recebido e a culpa relacionada ao que se pode oferecer ao outro. A gratidão é definida também como a capacidade de reconhecer aquilo que é oferecido pelo outro. Desta forma, para sentir-se grato deve-se conectar-se ao outro e ser capaz de reconhecer aquilo que ele o oferece como algo positivo, como algo bom. 
As acepções dos entrevistados coadunam com o que Klein (1957/1996) traz sobre a experiência de gratidão vivenciada na primeira relação com a figura materna, onde esta ao oferecer o alimento, o cuidado e o seu amor ao bebê promove a satisfação, influenciando assim na capacidade deste de ter prazer e de poder internalizar o seio bom, reconhecendo a mãe como um objeto de amor a partir do que ela oferece em seus aspectos bons. Tudo isso ajuda para que o bebê se desenvolva e que seu ego se fortaleça, fazendo com que essa identificação com as características boas da mãe seja o alicerce para boas identificações posteriores. Ter um mundo interno repleto de sentimentos e objetos bons faz com que os sujeitos sintam que estes correspondem ao seu amor e isso viabiliza dirigir sentimentos afetuosos aos outros.

A origem de tais sentimentos, ligados a fase inicial da infância e no relacionamento de exclusividade com a mãe oferecem a base que é construída no vínculo inicial mas que permeia também os vínculos posteriores estabelecidos ao longo da vida, nesse sentido, pode-se pensar que o sujeito que constrói essa base, poderia estabelecer um vínculo amoroso onde esse sentimento está presente.

Retomando as discussões desenvolvidas na introdução, pode-se questionar como esta base tem-se construído no cenário atual, diante do processo de fragilização das funções parentais (Zanetti \& Gomes, 2011), uma vez que nesse processo evidencia-se uma dificuldade dos pais de exercerem suas funções, dentre elas a de conter as angústias iniciais, oferecendo um suporte ao sujeito que possibilite construir a base de sua confiança nos objetos e de sua gratidão a eles, o que permite que ele se ligue e reconheça o outro de maneira integral.

Nas entrevistas realizadas, pode-se perceber que apesar da dificuldade de nomear e dar sentido à gratidão, os entrevistados a conectam à ideia de reconhecimento de algo bom que está no outro, porém apesar desse reconhecimento, não fica claro, se este é marcado pelo reconhecimento estabelecido a partir da troca, onde se vive um compartilhamento afetivo, uma troca que se baseia nessa relação inicial com a mãe e que se sustenta pelos vínculos posteriores que dão a ele essa gratificação possibilitada pelo investimento mútuo na relação de objeto, ou se esta se liga justamente a uma relação de consumo, onde eu nomeio a gratidão a partir do reconhecimento daquilo que o outro pode me oferecer, pautado pela lógica de consumo evidenciada por Bauman (2001) como um marcador dos modos de vida na sociedade atual.

Pode-se considerar a gratidão como uma forma de expressão das relações pautadas pelo consumismo, eu sou grato ao outro enquanto ele pode me oferecer algo que eu reconheço como bom. No relato de Vanessa, estas questões se evidenciam, uma vez que esta conecta a questão da gratidão ao reconhecimento, mas em seu caso, no reconhecimento de tudo aquilo que os pais puderam propiciar para ela e da necessidade de "pagar" tudo aquilo que 
recebeu, sendo a gratidão ligada a necessidade de retribuição ao outro do que Ihe foi oferecido. A necessidade de retribuição que se apresentou no relato de Vanessa, se articula ao que Klein fala da gratidão movida mais pelo sentimento de culpa do que pela capacidade de amar. Klein (1952/1996) discute a frustração do bebê e a criação de fantasias destrutivas contra o seio quando ele não o satisfaz, fazendo com que este sinta que o que desejou realmente tenha ocorrido, mobilizando a culpa e originando fantasias de reparação, de tentar restaurar esse objeto que foi danificado.

Essa gratidão relacionada a culpa do que o outro ofereceu, apresenta-se como um sentimento que se liga às experiências relacionais dos tempos atuais, onde suga-se do outro aquilo que ele pode oferecer e sente-se culpado em busca de uma retribuição que não vem, uma vez que a própria busca de ter algo do outro, que não seja a partir de uma experiência de troca, se relaciona ao fenômeno do narcisismo, onde eu quero o que outro pode me dar, e que não consigo retribuir pois meu ensimesmamento se deve justamente a uma defesa diante de minha situação desamparada, se articulando ao que é colocado por Rustin (2000), quando discute o narcisismo para Klein e coloca que este é tido como uma defesa diante da condição de desamparo que o sujeito se encontra, onde a troca não é possível e a gratidão se expressa pelo aquilo que o outro o oferece ligada à culpa de não se sentir potente para oferecer.

Nesse sentido, a gratidão na fala dos entrevistados aparece como algo muito importante, porém difícil de ser explicado, sendo conectado a capacidade de receber e reconhecer aquilo que é ofertado pelo outro. Porém, aparece nos relatos como algo vivido como um sentimento positivo, como a base dos relacionamentos amorosos, mas que não se evidencia por uma relação de troca, mas pelo "reconhecimento daquilo que o outro muda, oferece, agrega em sua vida" (Pedro), apontando para um sentimento que está presente nas relações amorosas, mas que dentro desse processo de transformação da sociedade e de mudanças nos modos de vida e subjetivação, se apresenta com uma roupagem atravessada pelo narcisismo como um operador cultural. Sinto-me grata ao outro não porque o reconheço como par de uma experiência afetiva, como na concepção construída nos textos de Klein (1957/1996), mas sinto-me grata por aquilo que o outro me oferece, aquilo que posso sugar dele e agregar a mim, aquilo que pode me proteger da dor da existência e da separação com objeto inicial, me dando muitas vezes a ilusão de retomada da segurança, da proteção e da satisfação perdidas.

\section{Categoria 3 - A gratidão e suas raízes}

Quando questionados sobre como aprenderam a ser gratos e sobre as experiências de gratidão vivenciadas nos relacionamentos, todos os entrevistados trouxeram a família como a base das experiências de gratidão. Ana e Pedro afirmam que aprenderam a ser gratos no berço e que isso é passado 
pelos pais pelas gerações o que, para Ana, já faz parte da sua cultura familiar. 0 fator herança é também trazido por João em sua fala:

porque eu tenho, como é que se fala, uma herança da minha mãe, porque minha mãe sempre passou isso pra gente lá em casa, principalmente eu, porque a gente sempre ouvia isso muito dela da gratidão, pra gente nunca esquecer o bem que alguém faz pra gente, sempre lembrar e parece que isso ficou gravado em mim isso [...]. (João)

Vanessa e Júlia também apontam a gratidão como algo que vem de suas famílias, porém Júlia diz que ao observar algumas pessoas de sua família que são "ingratas", tenta constantemente ser grata e reconhecer o que o outro faz por ela, e Vanessa coloca que deseja ser grata como os pais são e também conseguir oferecer a alguém algo sem esperar nada em troca.

Pensando as raízes do sentimento de gratidão e articulando à fala dos entrevistados ao que Klein (1957/1996) traz em suas reflexões sobre esse sentimento, pode-se dizer que a fala dos entrevistados apresenta um conflito com as ideias a autora. Para os entrevistados a gratidão está conectada ao que se é vivido no grupo familiar, é algo que vem do "berço", algo que é "herdado", ensinado pelos nossos pais, como um preceito que nós devemos seguir, a gratidão na fala dos entrevistados é colocada no campo do valor, um valor ensinado pelos pais e se distancia do sentimento descrito por Klein (1957/1996) que se constitui a partir da nossa capacidade inicial de amar e ser amado, investir e ser investido e sentir-se grato é uma resposta à satisfação vivenciada pela experiência de amor, de troca afetiva com nosso objeto inicial e esta tem ressonâncias por toda vida, como uma capacidade construída em nossas relações iniciais e que reflete nos vínculos posteriores que estabelecemos. Assim, as relações do sujeito carregam em sua gratidão uma base ligada à família, a relação inicial com o seio e a mãe e vão se moldando ao longo dos anos a partir de outras referências e outros contatos.

Para os entrevistados a gratidão tem suas raízes nas experiências familiares iniciais, mas pouco ou quase nada relataram sobre a gratidão como um sentimento, como uma experiência vivida no grupo familiar, a gratidão se apresenta como um valor, algo que deve ser passado pelos pais, algo que deve ser ensinado, e algo que se deve sentir em relação ao outro. Essas colocações se articulam às questões disparadoras desse artigo, a presença do termo gratidão nas redes sociais que levou a essas reflexões, trazem a essa compreensão, no cenário atual, a gratidão distancia-se da experiência, deixa de ser pensada como um sentimento, como algo vivido na relação de investimento e troca com o objeto, a gratidão figura o cenário social, como um valor, algo que deve ser aprendido e o sujeito grato é aquele que é reconhecido como um bom sujeito, afinal a gratidão passa a ser um valor, perdoando a redundância do termo, extremamente valorizado no cenário atual, onde somos o que podemos mostrar, 
evidenciar e explicitar por meio das mídias e redes sociais (Ferreira-Lemos, 2011).

Desta forma, aos entrevistados é possível falar sobre uma gratidão de berço, "aprende-se a ser grato" (Pedro), onde a gratidão é dada como um valor , como algo que permeia o imaginário social, influenciado também pelas doutrinas religiosas, de que "o bom sujeito, deve ser grato a aquilo que recebe" (Julia), sem conceber que a gratidão vai para além do eu para o seu objeto de investimento, ela pressupõe troca, reconhecimento, afetação mútua, algo que nos tempos atuais encontra-se como valores a serem pontuados e não como sentimentos e experiências a serem vividos. Os entrevistados destituem de afeto essa experiência e a tratam como um valor, como algo que se deve almejar e conquistar, e não a descrevem como algo que se sente em relação ao outro, algo que o conecta e que compõe as experiências vividas. Os elos estão frouxos, os vínculos familiares se enfraquecem, os investimentos empobrecem, e a gratidão deixa de ser sentimento, para ser tomado como um valor, algo a que me refiro quando penso naquilo que o outro me dá, me oferece, que me agrega, estando eu, sempre em primeiro lugar.

\section{Categoria 4 - A gratidão nos relacionamentos amorosos}

Ao serem questionados sobre o sentimento de gratidão com relação ao parceiro e sobre a presença desse sentimento em seu relacionamento, todos os entrevistados relataram sentirem-se gratos por estarem com seus parceiros. Para Julia, isso é demonstrado quando eles se declaram ao outro e ela localiza a gratidão como um agradecimento pelo cuidado ofertado, uma satisfação em ser cuidado. Para Ana, o sentimento de gratidão está presente a partir de sua leitura de que "a presença de um sempre melhorou a vida do outro". A gratidão para Ana é ligada a possibilidade de se sentir apoiado pelo outro, onde o outro acaba sendo um suporte, alguém que participa de sua vida e a melhora.

Nesse sentido, percebe-se que a gratidão para Ana preserva o sentido da gratidão apontado por Klein (1957/1996), como uma experiência de satisfação onde o sujeito vivencia a sensação de ser suportado e apoiado pelo outro, o outro como aquele que oferta o prazer e que faz com que o parceiro se sinta amado e amparado, mas Ana também traz questões do amor contemporâneo ao falar sobre a presença de um melhorar a vida do outro em sua relação e destaca que "a hora que não estiver mais melhorando a vida do outro não tem mais porque né". Bauman (2004) coloca que no cenário do amor líquido a relação amorosa é uma relação de consumo, sendo o outro objeto de prazer. A relação só é interessante e só faz sentido durante o tempo que o outro traz satisfação, pautando a relação com o objeto de forma parcial, não integrada, onde não se vê o objeto como o que traz aspectos bons e maus, sendo ele fonte de prazer e desprazer. 
Para Vanessa a gratidão está presente em sua relação, porém essa aponta que não sente que se doa para o parceiro e que recebe mais dele do que se dedica à relação. Para a entrevistada a gratidão está ligada ao que se faz para o outro e ao que se recebe dele e, como em todo seu relato, Vanessa demonstra uma certa dificuldade para falar da questão, dificuldade de retomar a experiência de gratidão e de demonstrar esse sentimento em suas relações. Seus relatos trazem uma dificuldade de sentir-se grata e de ofertar algo ao outro, como também de reconhecer aquilo que é ofertado pelo outro. Ela também nos traz a questão da fragilidade dos vínculos amorosos na contemporaneidade onde a preocupação com a própria performance e com aquilo que se ganha na relação, leva a empreender no relacionamento amoroso um jogo onde o que sustenta o vínculo é a lógica do "quem dá mais, quem ganha mais". Essa lógica de ganho no relacionamento contemporâneo alude as discussões de Bauman (2004) sobre a entrada numa relação pelo que se pode ganhar e a continuidade desta mediante a satisfação proporcionada aos parceiros, sendo esta a condição para se permanecer em tal relação. A satisfação proporcionada e o prazer que o outro dispõe passam a delimitar a relação de amor sendo esse outro valorizado pelo que aparenta e não pelo que é.

João diz que gostaria de perceber mais a gratidão, e acha que precisava um pouco mais deste sentimento, pois o que percebe é pouco e espera a atitude mais da parceira. O entrevistado também traz algumas contradições em sua fala quando diz que tenta demonstrar a gratidão, mas a seguir também diz sentir que deixa a desejar, que poderia ser mais grato e acaba não conseguindo responder o porquê de sentir grato por estar com esposa. No relato de João evidencia-se uma dificuldade em pensar a gratidão na experiência amorosa, este diz que esperava mais gratidão da parte da esposa, mas também aponta que considera que poderia ser mais atento a expressar sua gratidão a ela.

O relato de João quando coloca que precisava mais desse sentimento, pode ser pensado a partir da lógica consumo que permeia as relações na atualidade, a gratidão aparece para ele como algo que ele precisa de mais, como se fosse algo que ele e a parceira pudessem consumir, algo que deve estar na relação e se tem como um objetivo ser grato. Gratidão vira uma meta. A gratidão em seu relato, como no de Ana, aparece pela dificuldade de pensar o vínculo conjugal a partir das experiências e sentimentos, aparece como algo a ser conquistado, consumido e que dá a relação uma valorização social, na lógica de que: relações onde os sujeitos são gratos, são mais valorizadas no cenário atual. Porém, o que não se percebe é que essa valorização é pautada pela lógica do narcisismo e do consumismo, que levam o sujeito a um esvaziamento afetivo e da experiência da troca com o outro, pautando-se por uma valorização da própria performance e daquilo que a sociedade aponta como modos ideais de se viver, que atravessam também as relações de amor. 
Enriquez (2006) e Birman (2006), ao refletirem sobre os modos e vida e subjetivação na contemporaneidade, apontam que a vida na atualidade é marcada por um pensamento automático e prático ligado a fatores do cotidiano, a vida segue um "script" pré-estabelecido, onde ser feliz é uma meta na ordem prática e onde os sujeitos se distanciam da experiência de sentidos. Fala-se do amor na ordem prática, da rotina amorosa, fala-se da vida a partir do cotidiano e dos acontecimentos, pouco se fala do que se sente, de como se sente e das experiências do sentir. Vivemos na atualidade um esvaziamento dessa experiência de sentir e isso nos traz uma dificuldade de refletir sobre nossos sentimentos quando somos questionados sobre eles. Assim, se apresentou a gratidão para os entrevistados, distante de um sentimento vivenciado, de uma experiência que compõe o sujeito e tem ressonâncias nas suas relações, mas sim como um valor, uma meta, algo que se deve ter, para consumir ou se valorizar.

\section{CONSIDERAÇÕES FINAIS}

A partir do desenvolvimento deste estudo, pode-se compreender que a gratidão apresenta sentidos diversos a partir das experiências das pessoas entrevistadas, porém estas trazem como ponto comum quando a definem como um reconhecimento do parceiro do que ele faz para o outro, do que ele agrega a sua vida. O termo gratidão apresentou-se nos relatos não como um sentimento vivido na experiência de uma relação com o outro, mas como um valor ligado à família e passado por ela.

A gratidão nas relações amorosas, além de aparecer com a roupagem de um valor pessoal e social, evidencia também uma dificuldade de se pensar o vínculo conjugal a partir das experiências e sentimentos, onde prepondera a lógica do narcisismo e do consumismo. Esse movimento, leva o sujeito a um esvaziamento afetivo e da experiência da troca com o outro, e emergem nesse cenário relações baseadas na valorização da própria performance e daquilo que a sociedade aponta como modos ideais de se viver.

Nesse sentido, a gratidão como um valor aparece como uma das formas de expressão das configurações das relações amorosas na atualidade, pautadas pelo consumismo e pelo narcisismo. A gratidão é destituída do afeto da experiência de troca com o outro, mas constituída como o que se deve almejar e conquistar. Pensar a gratidão nas relações amorosas na atualidade leva a reflexão sobre a fragilidade dos vínculos, dos investimentos e do esvaziamento da experiência e dos sentimentos.

Assim, pautando as reflexões nos apontamentos kleinianos, seria possível observar que na atualidade essa fragilidade atravessa também os investimentos iniciais onde a relação com o objeto inicial se apresenta de forma pouco integrada, não sendo possível construir uma base segura e sólida na qual o sujeito se sinta seguro e potente para investir em um outro objeto para além da 
busca do que ele pode oferecer, mas na possibilidade de reconhece-lo de forma integral e suportar a vivência de sentimentos ambivalentes com relação a ele. A fragilidade das relações amorosas, se caminharmos na guisa dessas reflexões, se relaciona à fragilidade dos investimentos iniciais e de um contexto onde as primeiras relações também se fragmentam em uma sociedade pautada na autoperformance, no autocuidado e na espetacularização de tudo.

A gratidão tem então o sentido do valor que garante a continuidade de uma "vida espetacular", onde os amantes são os atores num palco, mas num palco onde o que se busca não é o aplauso do compartilhamento, da troca, da afetação, é a valorização da plateia, que sustenta a satisfação que se volta para si, que solidifica as defesas diante do desamparo.

\section{DECLARAÇÃO DE CONFLITOS DE INTERESSE}

As autoras declaram que não houve conflitos de interesse.

\section{REFERÊNCIAS}

Baudrillard, J. (2007). A sociedade de consumo. Lisboa: Edições 70.

Bauman, Z. (2001). Modernidade líquida. Rio de Janeiro: Jorge Zahar.

Bauman, Z. (2004). Amor líquido: sobre a fragilidade dos laços humanos. Rio de Janeiro, Zahar.

Birman, J. (2006). Arquivos do mal estar e da resistência. Rio de Janeiro: Civilização Brasileira.

Costa, J. F. (1998). Sem fraude nem favor: estudos sobre o amor romântico. Rio de Janeiro: Rocco.

Enriquez, E. (2006) O homem do século XXI: sujeito autônomo ou indivíduo descartável. RAE - Revista Administração de Empresas, 5(1), 10-14. Recuperado em 20 de novembro de 2017 de: http://rae.fgv.br/raeeletronica/vol5-num1-2006/homem-seculo-xxi-sujeito-autonomo-ouindividuo-descartavel.

Ferreira-Lemos, P. P. (2011). Navegar é fantasiar: relações virtuais e psicanálise. Psico, 42(1), 59-66. Recuperado em 20 de outubro de 2017 de: http://revistaseletronicas.pucrs.br/ojs/index.php/revistapsico/article/view/6 454.

Figueiredo, L. C., \& Minerbo, M. (2006). Pesquisa em psicanálise: algumas idéias e um exemplo. Jornal de Psicanálise, 39(70), 257-278. Recuperado em 10 de novembro de 2017 de http://pepsic.bvsalud.org/scielo.php?script=sci_arttext\&pid=S0103$58352006000100017 \&$ Ing $=$ pt\&tlng $=p t$. 
Freud, S. (1996). Sobre o narcisismo: uma introdução. In S. Freud, A história do movimento psicanalítico, artigos sobre a metapsicologia e outros trabalhos (pp. 77-108; Vol. XIV; Edição Standard Brasileira das Obras Psicológicas Completas de S. Freud). Rio de Janeiro: Imago (Originalmente publicado em 1914).

Kenberg, O. F. (1995). Psicopatologia das relações amorosas. Porto Alegre: Artes Médicas.

Klein, M. (1996). Amor, culpa e reparação. In Obras completas de Melanie Klein. (Vol. I). Rio de Janeiro: Imago. (Trabalho original publicado em 1952).

Klein, M. (1996). Inveja e gratidão. In Obras completas de Melanie Klein. (Vol. III). Rio de Janeiro: Imago. (Trabalho original publicado em 1957).

Lasch, C. (1983). A cultura do narcisismo. Rio de Janeiro: Imago.

Lins, R. N. (2012). O livro do amor volume 2: do Iluminismo à Atualidade. Rio de Janeiro: Best Seller.

Lipovetsky, G. (2005). A era do vazio: ensaios sobre o individualismo contemporâneo. São Paulo: Manole.

Oliveira, G. A. R. (2006). Escolhas narcísicas de objeto e relações amorosas na atualidade. Dissertação de Mestrado, Universidade Católica de Goiás, Goiânia.

Ramos, M. (2003). Novas parcerias, novos conflitos. In P. B. Gomes (Org), Vínculos amorosos contemporâneos (pp. 57-75). São Paulo: Callis.

Rossi, C. (2003). Os novos vínculos conjugais: vicissitudes e contradições. In: P. B. Gomes (Org.), Vínculos Amorosos Contemporâneos (pp. 77-108). São Paulo: Callis.

Rodrigues, I. C. (2013). Efeitos da regulação das necessidades psicológicas na manutenção e na satisfação em relações amorosas estáveis. Dissertação de Mestrado, Faculdade de Psicologia, Universidade de Lisboa, Lisboa.

Roudinesco, E. e Plon, M. Dicionário de Psicanálise. Rio de Janeiro: Zahar, 1998.

Rustin, M. (2000). A boa sociedade e o mundo interno. Psicanálise, Política e Cultura. Rio de Janeiro: Imago.

Sá, R. N., Mattar, C. M., \& Rodrigues, J. T. (2006). Solidão e relações afetivas na era da técnica. Revista do Departamento de Psicologia - UFF, 18(2), 111124. doi: http://dx.doi.org/10.1590/S0104-80232006000200009

Smeha, L. N., \& Oliveira, M. V. (2013). Os relacionamentos amorosos na contemporaneidade sob a ótica dos adultos jovens. Psicologia: Teoria e Prática, 15(2), 33-45. Recuperado em 09 de abril de 2017, de http://pepsic.bvsalud.org/scielo.php?script=sci_arttext\&pid=S151636872013000200003\&lng=pt\&tlng $=$ pt. 
Zanetti, S. A. S., \& Gomes, I. C. (2011). A "fragilização das funções parentais" na família contemporânea: determinantes e consequências. Temas em Psicologia, 19(2), 491-502. Recuperado em 04 de outubro de 2016, de http://pepsic.bvsalud.org/scielo.php?script=sci_arttext\&pid=S1413$389 \times 2011000200012 \&$ lng $=p t \& t$ lng $=p t$.

Zanetti, S. A. S. (2012). A opção por não se vincular amorosamente de maneira compromissada entre as condições de existências contemporâneas e a herança psíquica geracional. Tese de Doutorado, Universidade de São Paulo, São Paulo.

Sobre os autores

Thassia Souza Emidio é Professora Assistente Doutora do Departamento de Psicologia Clínica. Graduação, Mestrado e Doutorado pela Universidade Estadual Paulista "Júlio de Mesquita Filho" - UNESP- Faculdade de Ciências e Letras de Assis. e-mail: emidioth@hotmail.com

Jussara Aparecida Rodrigues é Psicóloga formada pela Universidade Estadual Paulista "Júlio de Mesquita Filho" - UNESP - Faculdade de Ciências e Letras de Assis.e-mail: juh_rodriguesb3@hotmail.com

Thassia e Jussara construíram a pesquisa em conjunto, Jussara realizou as entrevistas e a redação inicial da análise dos dados e do artigo. Thassia deu continuidade à análise dos dados sendo responsável pela redação final do artigo.

As autoras agradecem a Fundação de Amparo à Pesquisa do Estado de São Paulo - FAPESP pelo financiamento da pesquisa.

Recebido em: 23/08/2017

$1^{\text {a. }}$ Revisão em: $13 / 12 / 2017$

$2^{a}$. Revisão em: 06/02/2018

Aceito em: 16/02/2018 